\title{
Aids e tuberculose: a coinfecção vista pela perspectiva da qualidade de vida dos indivíduos*
}

\author{
AIDS AND TUBERCULOSIS: COINFECTION FROM THE PERSPECTIVE OF THE \\ QUALITY OF LIFE OF PATIENTS
}

\section{SIDA Y TUBERCULOSIS: LA COINFECCIÓN VISTA SEGÚN LA PERSPECTIVA DE LA CALIDAD DE VIDA DE LOS INDIVIDUOS.}

\author{
Lis Aparecida de Souza Neves ${ }^{1}$, Sílvia Rita Marin Canini ${ }^{2}$, Renata Karina Reis ${ }^{3}$, \\ Cláudia Benedita dos Santos ${ }^{4}$, Elucir Gir $^{5}$
}

\section{RESUMO}

A coinfecção tuberculose (TB) e HIV afeta negativamente a vida dos indivíduos, tanto nos aspectos biológicos como nos psicossociais. Com o objetivo de descrever a qualidade de vida de indivíduos com coinfecção HIV/TB, foi realizado este estudo descritivo, de corte transversal, no município de Ribeirão Preto-SP. Foram entrevistados indivíduos soropositivos para o HIV, com e sem TB, por meio do instrumento WHOQOL-HIV bref. Participaram 115 indivíduos soropositivos para o HIV - 57 coinfectados e 58 não coinfectados; a maioria do sexo masculino, heterossexuais, faixa etária predominante de 40-49 anos, com os coinfectados apresentando baixas escolaridade e renda; na avaliação da qualidade de vida os coinfectados apresentaram resultados mais baixos em todos os domínios, com diferença importante no Físico, Psicológico, Nível de Independência e Relações Sociais. TB e HIV/aids são doenças estigmatizadas historicamente e a sobreposição das duas pode ter consequências graves na saúde física e psicossocial do indivíduo.

\section{DESCRITORES}

Tuberculose

Síndrome de Imunodeficiência Adquirida HIV

Qualidade de vida

\section{ABSTRACT}

Tuberculosis (TB) and HIV coinfection adversely affects the lives of individuals in both the biological and psychosocial aspects. Aiming to describe the quality of life of individuals with HIV/TB coinfection, this descriptive cross-sectional study was conducted in Ribeirão Preto-SP. Participants were HIV-seropositive individuals with and without TB, using the WHOQOL HIV BREF. 115 individuals who were HIV-positive participated: 57 were coinfected and 58 were not; most were male heterosexuals, predominantly aged $40-49$ years. Of those coinfected, most had lower education and income. In assessing the quality of life the coinfected individuals showed lower results in all areas, with significant differences in the Physical, Psychological, Level of Independence and Social Relations areas. TB and HIV / AIDS are stigmatized diseases, and overlap of the two may have severe consequences on the physical and psychosocial health of the individual.

\section{DESCRIPTORS}

Tuberculosis

Acquired Immunodeficiency Syndrome HIV

Quality of life

\section{RESUMEN}

La coinfección tuberculosis (TB) y HIV afecta negativamente la vida del individuo, tanto en los aspectos biológicos como en los psicosociales. Objetivando describir la calidad de vida de individuos con coinfección HIV/TB se realizó este estudio descriptivo, de corte transversal, en el municipio de Ribeirão Preto-SP. Fueron entrevistados individuos seropositivos para HIV, con o sin TB, mediante instrumento WHOQOL-HIV bref. Participaron 115 individuos seropositivos para HIV, 57 coinfectados y 58 no coinfectados, la mayoría de sexo masculino, heterosexuales, faja etaria predominante de 40-49 años, los coinfectados presentando escolaridad e ingresos inferiores; en la evaluación de calidad de vida los coinfectados presentaron resultados más bajos en todos los dominios, con diferencias importantes en el Físico, Psicológico, Nivel de Independencia y Relaciones Sociales. TB y HIV/SIDA son enfermedades históricamente estigmatizadas, la superposición de ambas puede tener graves consecuencias en la salud física y psicosocial del individuo.

\section{DESCRIPTORES}

Tuberculosis

Síndrome de Inmunodeficiencia Adquirida $\mathrm{VIH}$

Calidad de vida

\footnotetext{
* Extraído da tese "Qualidade de vida de indivíduos com a coinfecção HIV/tuberculose no município de Ribeirão Preto - SP", Escola de Enfermagem de Ribeirão Preto, Universidade de São Paulo, 2010. ${ }^{1}$ Enfermeira. Doutora em Ciências pela Escola de Enfermagem de Ribeirão Preto da Universidade de São Paulo. Enfermeira da Secretaria Municipal da Saúde de Ribeirão Preto. Ribeirão Preto, SP, Brasil. lisapneves@yahoo.com.br ${ }^{2}$ Enfermeira. Professora Doutora da Escola de Enfermagem de Ribeirão Preto da Universidade de São Paulo. Ribeirão Preto, SP, Brasil. canini@eerp.usp.br ${ }^{3}$ Enfermeira. Professora Doutora do Departamento de Enfermagem da Universidade Federal de Alagoas. Maceió, AL, Brasil. renakari2006@hotmail.com ${ }^{4}$ Doutora em Estatística. Professora Associada da Escola de Enfermagem de Ribeirão Preto da Universidade de São Paulo. Ribeirão Preto, SP, Brasil. cbsantos@eerp.usp.br ${ }^{5}$ Enfermeira. Professora Titular da Escola de Enfermagem de Ribeirão Preto da Universidade de São Paulo. Ribeirão Preto, SP, Brasil. egir@eerp.usp.br
} 


\section{INTRODUÇÃO}

A infecção pelo HIV aumenta significativamente o risco de desenvolvimento de tuberculose (TB) ativa: um indivíduo infectado pelo HIV é 25 vezes mais susceptível à TB em relação aos não infectados, e o risco de morte em pacientes coinfectados pelo HIV e pelo bacilo de Koch é duas vezes maior que em paciente soropositivo para o HIV sem $\mathrm{TB}^{(1)}$.

A associação desta coinfecção é sinérgica, interativa e recíproca, com impacto significativo no curso das duas patologias. A coinfecção é responsável pelo aumento dos índices de mortalidade, tornando-se um desafio para a saúde pública(2).

Antes dos anos 90, havia pouca solução terapêutica para arrefecer os efeitos da ação do HIV no indivíduo. O advento da terapia antirretroviral (TARV) para o tratamento dos indivíduos com HIV/aids, proporcionou aumento no tempo de sobrevida, porém, a infecção pelo HIV assumiu características crônico-degenerativas, com efeitos relacionados ao convívio de longo tempo com o vírus, suas comorbidades e os efeitos adversos do tratamento ${ }^{(3)}$.

A melhoria clínica dos pacientes infectados pelo HIV sob terapia ARV foi muitas vezes medida pela redução na mortalidade, as taxas de infecção oportunistas ou graves sintomas relacionados com aids. A avaliação da qualidade de vida (QV) pode ser usada para monitorar o impacto da doença, podendo ser clinicamente útil para identificar quais aspectos são mais afetados por intervenções diretas, além de mensurar resultados de tratamentos ${ }^{(4)}$.

O interesse crescente na avaliação da qualidade de vida (QV) inclui também os doentes de TB, que mesmo sendo uma doença curável, apresenta tratamento de longa duração, com impacto na vida dos pacientes ${ }^{(5)}$, e com resultados mais baixos que os da população geral(6).

Para medir a QV, dois tipos de instrumentos são utilizados: os genéricos que abrangem os aspectos comuns e importantes da saúde e podem ser usados para avaliar e comparar a QV em diferentes condições de saúde e sub-populações; ou os específicos que são aqueles construídos para avaliação de determinadas doenças crônicas ${ }^{(5)}$.

Diversos instrumentos específicos para indivíduos com HIV foram encontrados na literatura internacional, mas somente o HAT-Qol e o WHOQOL HIV foram validados para o Brasil. Já em relação à $T B$, os estudos internacionais encontrados utilizaram instrumentos genéricos, como o SF-36 e o MOS, e um instrumento específico criado e utilizado apenas na Índia, o DR-12(5).

Para o presente estudo, optou-se por utilizar o instrumento da Organização Mundial de Saúde (OMS), versão abreviada - o WHOQOL HIV bref, sendo adotado o conceito de qualidade de vida definido pelo Grupo de Qualidade de Vida da OMS:

a percepção do indivíduo de sua posição na vida, no contexto da cultura e sistema de valores nos quais ele vive e em relação aos seus objetivos, expectativas, padrões e preocupações $^{(7)}$.

Vale ressaltar que, apesar da importância epidemiológica da TB no Brasil, não foram encontrados estudos nacionais sobre QV em pacientes com TB e em coinfectados com HIV/aids. Existe necessidade de estudos que identifiquem as variáveis relacionadas a QV em populações locais, visando não só propor intervenções no âmbito da saúde física e mental, mas também contribuir para as políticas públicas de saúde que impliquem em melhoria na qualidade de vida dos pacientes.

\section{OBJETIVO}

Descrever a qualidade de vida de indivíduos com a coinfecção HIV/TB e comparar com a dos indivíduos soropositivos para o HIV sem TB.

\section{MÉTODO}

Trata-se de um estudo descritivo, de corte transversal, realizado por meio de entrevista individual com indivíduos soropositivos para o HIV, com e sem TB.

A população foi composta por todos os pacientes coinfectados HIV/TB de ambos os sexos em seguimento clínico ambulatorial nas unidades especializadas de Ribeirão Preto-SP, que aquiescerem em participar do estudo, atendendo aos critérios de inclusão: ter resultado de exame sorológico reagente para HIV; estar em seguimento ambulatorial para tratamento de HIV/aids; idade superior ou igual a 18 anos; diagnóstico confirmado de TB; ter condições físicas, mentais e psicológicas para participar da entrevista.

Como critério de exclusão considerou-se a situação de confinamento (presidiários).

Para a identificação dos indivíduos coinfectados, mensalmente era solicitado ao Coordenador do Programa de Tuberculose da Secretaria Municipal da Saúde, a relação dos pacientes notificados no município, segundo o resultado do exame para HIV e ambulatório que notificou. As entrevistas eram então agendadas e realizadas de acordo com a disponibilidade do paciente.

Para compor o grupo de soropositivos para o HIV não coinfectados, foram selecionados indivíduos que compareceram aos retornos ambulatoriais durante o período de coleta dos dados, considerando-se os mesmos critérios de 
inclusão e exclusão, na proporção de 1:1 com o grupo de coinfectados. Para diminuir eventuais fatores de confusão relacionados ao gênero, foi feito o pareamento deste grupo de acordo com o sexo.

Foi utilizado um questionário para caracterização socioeconômica, epidemiológica e clínica e o instrumento WHOQOL HIV-bref. O WHOQOL HIV-bref é composto de 31 questões, divididas em seis domínios: físico, psicológico, nível de independência, relações sociais, meio ambiente e espiritualidade ${ }^{(7)}$.

O domínio físico é composto pelos ítens: dor e desconforto, energia e fadiga, sono e repouso, sintomas; o domínio psicológico envolve sentimentos positivos e negativos, cognição, auto-estima, imagem corporal e aparência; o domínio nível de independência relaciona-se a mobilidade, atividades da vida cotidiana, dependência de tratamento e aptidão ao trabalho; o domínio relações sociais inclui: relações pessoais, suporte social, atividade sexual e inclusão social; o domínio meio ambiente envolve segurança física, moradia, finanças, cuidados de saúde e sociais, informação, lazer; ambiente físico e transporte; e o domínio espiritualidade relaciona os itens espiritualidade, religião, perdão e culpa, preocupações com o futuro e morte.

Para o cálculo global de cada domínio, que varia entre quatro e 20 , utilizou-se a equação sugerida pela $\mathrm{OMS}^{(7)}$. Os dados foram descritos em médias e desvios-padrão. Utilizou-se o teste Kolmogorov-Smirnov para avaliar a normalidade das distribuições. Para analisar eventuais diferenças entre médias dos escores de qualidade de vida, foi utilizado o teste t-Student. 0 nível de significância estatística adotado foi de $5 \%(\alpha=0,05)$.

O período de coleta transcorreu de fevereiro de 2008 a fevereiro de 2010. Todos os pacientes coinfectados estavam sob tratamento supervisionado.

O estudo foi aprovado pelo Comitê de Ética em Pesquisa da Escola de Enfermagem de Ribeirão Preto - USP, protocolo 0858/2007; as entrevistas foram realizadas após o esclarecimento e concordância dos sujeitos, e após a assinatura do Termo de Consentimento Livre e Esclarecido.

\section{RESULTADOS}

No ano de 2008 e 2009, no município de Ribeirão Preto foram notificados 391 pacientes com TB sendo que 84 $(21,5 \%)$ apresentavam sorologia positiva para o HIV. Foram entrevistados 57 pacientes coinfectados HIV/TB que atendiam aos critérios de inclusão e 58 indivíduos soropositivos para o HIV sem TB que estavam em acompanhamento ambulatorial, totalizando 115 participantes do estudo.

Do total de participantes, $86(74,8 \%)$ eram do sexo masculino, com idade média de 40 anos, variando entre 18 e 62 anos; a faixa etária predominante foi dos 40 aos 49 anos (40,9\%).

As características socioeconômicas e epidemiológicas da população do estudo estão apresentadas na Tabela 1.

Na Tabela 2 estão apresentadas as características clínicas dos entrevistados.

Tabela 1 - Distribuição dos indivíduos com HIV/aids, segundo a coinfecção tuberculosa, variáveis socioeconômicas e valores das probabilidades associadas aos testes estatísticos - Ribeirão Preto, SP - 2008/2009

\begin{tabular}{|c|c|c|c|c|c|c|c|}
\hline \multirow{2}{*}{ Variáveis } & \multicolumn{2}{|c|}{ Com TB } & \multicolumn{2}{|c|}{ Sem TB } & \multicolumn{2}{|c|}{ Total } & \multirow{2}{*}{$\mathbf{p}$} \\
\hline & $\mathbf{N}$ & $\%$ & $\mathbf{N}$ & $\%$ & $\mathbf{N}$ & $\%$ & \\
\hline \multicolumn{8}{|l|}{$\operatorname{Sexo}^{(a)}$} \\
\hline Masculino & 43 & 75,4 & 43 & 74,1 & 86 & 74,8 & $1,000^{(\mathrm{ns})}$ \\
\hline Feminino & 14 & 24,6 & 15 & 25,9 & 29 & 25,2 & \\
\hline \multicolumn{8}{|l|}{ Idade (anos) ${ }^{(b)}$} \\
\hline 18 a 29 & 9 & 15,8 & 5 & 8,6 & 14 & 12,2 & $0,260^{\text {(ns) }}$ \\
\hline 30 a 39 & 18 & 31,6 & 23 & 39,7 & 41 & 35,7 & \\
\hline 40 a 49 & 24 & 42,1 & 23 & 39,7 & 47 & 40,8 & \\
\hline$\geq 50$ & 6 & 10,5 & 7 & 12,1 & 13 & 11,3 & \\
\hline \multicolumn{8}{|l|}{ Escolaridade $^{\text {(a) }}$} \\
\hline Analfabeto & 5 & 8,8 & 3 & 5,2 & 8 & 7,0 & $0,001 * *$ \\
\hline Ensino fund. incompleto & 34 & 59,6 & 31 & 53,4 & 65 & 56,5 & \\
\hline Ensino fund. completo & 16 & 28,1 & 7 & 12,1 & 23 & 20,0 & \\
\hline Ensino médio ou mais & 2 & 3,5 & 17 & 29,3 & 20 & 16,5 & \\
\hline \multicolumn{8}{|l|}{ Renda (salário mínimo) ${ }^{(b)}$} \\
\hline Até 1 & 23 & 40,4 & 12 & 20,7 & 35 & 30,4 & $0,001 * *$ \\
\hline 1,1 a 3 & 29 & 50,9 & 38 & 65,5 & 67 & 58,3 & \\
\hline$>3$ & 5 & 8,8 & 8 & 13,8 & 13 & 11,3 & \\
\hline \multicolumn{8}{|l|}{ Orientação sexual (a) $^{(a)}$} \\
\hline Homossexual & 8 & 14,0 & 12 & 20,7 & 20 & 17,4 & $0,487^{\text {(ns) }}$ \\
\hline Heterossexual & 49 & 86,0 & 46 & 79,3 & 95 & 82,6 & \\
\hline \multicolumn{8}{|l|}{ Categoria de exposição ${ }^{\mathrm{NR}}$} \\
\hline Sexual & 49 & 86,0 & 54 & 93,0 & 103 & 89,6 & --- \\
\hline Uso de drogas injetáveis & 5 & 8,8 & 2 & 3,5 & 7 & 6,1 & \\
\hline Não sabe & 3 & 5,2 & 2 & 3,5 & 5 & 4,3 & \\
\hline
\end{tabular}

Obs.: Salário mínimo vigente na época do estudo: $R$ \$ 415,00 em 2008 e R\$ 465,00 em 2009; (a) teste qui-quadrado; (b) teste t de Student;

${ }^{*} 0,01<p<0,05 ;{ }^{* *} p<0,01 ;$ ns: não significativo. 
Tabela 2 - Distribuição dos indivíduos com HIV/aids, segundo a coinfecção tuberculosa, variáveis clínicas e valores das probabilidades associadas aos testes estatísticos - Ribeirão Preto, SP - 2008/2009

\begin{tabular}{|c|c|c|c|c|c|c|c|}
\hline \multirow{2}{*}{ Variáveis } & \multicolumn{2}{|c|}{ Com TB } & \multicolumn{2}{|c|}{ Sem TB } & \multicolumn{2}{|c|}{ Total } & \multirow{2}{*}{$\mathbf{p}$} \\
\hline & $\mathbf{N}$ & $\%$ & $\mathbf{N}$ & $\%$ & $\mathbf{N}$ & $\%$ & \\
\hline \multicolumn{8}{|c|}{ Tempo de ciência do HIV (meses) ${ }^{(a)}$} \\
\hline$\leq 6$ & 17 & 29,8 & 5 & 8,6 & 22 & 19,1 & $0,009 * *$ \\
\hline$\overline{7}$ a 60 & 13 & 22,8 & 22 & 38,0 & 35 & 30,4 & \\
\hline 61 a 120 & 16 & 28,1 & 12 & 20,7 & 28 & 24,3 & \\
\hline$\geq 121$ & 11 & 19,3 & 19 & 32,7 & 30 & 26,1 & \\
\hline \multicolumn{8}{|c|}{ Linfócitos T CD4 (células/ mm³ de sangue) ${ }^{(\mathrm{b})}$} \\
\hline$\leq 200$ & 42 & 73,7 & 25 & 43,1 & 67 & 58,3 & $0,000 * *$ \\
\hline 201 a 350 & 10 & 17,5 & 16 & 27,6 & 26 & 22,6 & \\
\hline$\geq 351$ & 5 & 8,8 & 17 & 29,3 & 22 & 19,1 & \\
\hline \multicolumn{8}{|c|}{ Carga viral (cópias RNA viral/ml) ${ }^{(b)}$} \\
\hline Indetectável & 4 & 7,0 & 33 & 56,9 & 37 & 32,2 & $0,000 * *$ \\
\hline 51 a 20.000 & 9 & 15,8 & 10 & 17,2 & 7 & 6,1 & \\
\hline 20.001 a 100.000 & 26 & 45,6 & 9 & 15,5 & 47 & 40,8 & \\
\hline$\geq 100.000$ & 18 & 31,6 & 6 & 10,4 & 24 & 20,9 & \\
\hline \multicolumn{8}{|l|}{ Uso de ARV (a) } \\
\hline Sim & 37 & 64,9 & 56 & 96,6 & 93 & 80,9 & $0,000 * *$ \\
\hline Não & 20 & 35,1 & 2 & 3,4 & 22 & 19,1 & \\
\hline \multicolumn{8}{|c|}{ Forma clínica da TB } \\
\hline Pulmonar & 34 & 59,6 & - & - & 34 & 59,6 & \\
\hline Extra-pulmonar & 23 & 40,4 & - & - & 23 & 40,4 & \\
\hline \multicolumn{8}{|c|}{ Tempo de tratamento TB } \\
\hline$\leq 60$ & 13 & 22,8 & - & - & 13 & 22,8 & \\
\hline 61 a 180 & 38 & 66,7 & - & - & 38 & 66,7 & \\
\hline$\geq 181$ & 6 & 10,5 & - & - & 6 & 10,5 & \\
\hline
\end{tabular}

(a): teste qui-quadrado; ${ }^{(b)}$ : teste t-Student; ${ }^{*}: 0,01<p<0,05 ;{ }^{* *}: p<0,01 ;$ ns: não significativo.

O WHOQOL HIV bref foi submetido à avaliação de confiabilidade utilizando-se o coeficiente Alpha de Cronbach, tendo apresentado valores que variaram de 0,69 a 0,74, demonstrando boa consistência interna do instrumento.

Em relação à $Q V$, os resultados obtidos estão apresentados na Tabela 3.

Tabela 3 - Escores médios, respectivos desvios-padrão, e valores das probabilidades associadas ao teste $t$ de Student para cada um dos domínios do WHOQOL HIV bref dos indivíduos com HIV/aids, segundo a coinfecção tuberculosa - Ribeirão Preto, SP - 2008/2009

\begin{tabular}{lccc}
\hline Domínios & Média & DP & $\mathbf{p}^{*}$ \\
\hline Físico & & & \\
Com TB & 12,07 & 3,67 & $0,000^{* *}$ \\
Sem TB & 14,82 & 3,34 & \\
\hline Psicológico & & & \\
Com TB & 13,57 & 2,99 & $0,027^{*}$ \\
Sem TB & 14,80 & 2,86 & \\
\hline Nível de Independência & & \\
Com TB & 11,42 & 2,96 & $0,000^{* *}$ \\
Sem TB & 13,60 & 2,64 & \\
\hline Relações Sociais & & & \\
Com TB & 13,14 & 2,79 & $0,028^{*}$ \\
Sem TB & 14,39 & 3,22 & \\
\hline Meio Ambiente & & & \\
Com TB & 13,05 & 1,91 & 0,189 \\
Sem TB & 13,65 & 2,87 & \\
\hline Espiritualidade & & & \\
Com TB & 14,80 & 3,51 & 0,585 \\
Sem TB & 15,17 & 3,64 & \\
\hline
\end{tabular}

* $0,01<p<0,05$; ** $p<0,01$; ns: não significativo; Valores do WHOQOL: de 4 a 20.
Foi identificada diferença estatisticamente significante entre os dois grupos nos domínios Físico $(p<0,01)$, Psicológico $(p=0,027)$, Nível de Independência $(p<0,01)$ e Relações Sociais $(p=0,028)$, com o grupo de pacientes coinfectados apresentando escores médios inferiores aos do grupo sem a coinfecção. O domínio Nível de Independência apresentou a pior média para os dois grupos e Espiritualidade foi o melhor também para ambos.

\section{DISCUSSÃO}

Dentre os participantes do grupo de coinfectados, $75,4 \%$ eram do sexo masculino. O predomínio do sexo masculino, tanto na TB como na aids, também é descrito em outros estudos em diferentes localidades do Brasil desde o início da década de 1990, confirmando a população masculina como mais vulnerável e prevalente para coinfecção por $M t b$ e $\mathrm{HIV}^{(8)}$.

Quanto à escolaridade e renda, coincidem com o perfil social da epidemia de aids e de TB, que no Brasil atinge principalmente a população das camadas menos favorecidas economicamente ${ }^{(3,9-10)}$. Porém, no grupo dos coinfectados, estes indicadores foram ainda mais baixos que os demais. A baixa escolaridade evidencia uma vulnerabilidade social, uma vez que influencia o indivíduo em relação à obtenção de informações de maneira geral e mais especificamente sobre a doença ${ }^{(11)}$.

Quase um terço dos pacientes coinfectados tomou conhecimento de sua soropositividade praticamente ao 
mesmo tempo em que a TB foi diagnosticada, ressaltando a importância da realização do teste anti-HIV nestes pacientes $^{(12)}$. Por outro lado, o fato de que $27(47,4 \%)$ indivíduos fossem sabidamente soropositivos há mais de cinco anos, reforçam a necessidade de pesquisar e prevenir a TB entre os pacientes com HIV/aids.

Nos indivíduos do presente estudo, observou-se que os coinfectados apresentaram níveis de contagem de células T CD4 menores do que os com HIV/aids e carga viral maiores, corroborando com a literatura e indicando que a TB é uma infecção oportunista fortemente associada à queda do sistema imunológico ${ }^{(8,13)}$.

Quanto ao uso de ARV, o maior percentual de indivíduos não coinfectados em uso do tratamento medicamentoso poderia ser justificado pelo fato de que os indivíduos que descobriram o diagnóstico de HIV recentemente e ainda não começaram a tomar os medicamentos ARV; outro fator a ser considerado, é que os pacientes coinfectados que sabiam sua condição sorológica há mais tempo, não tinham boa adesão ao tratamento, aumentando a possibilidade de desenvolverem a TB.

Os domínios da QV com diferença estatisticamente significante entre os indivíduos com e sem coinfecção foram Físico, Psicológico, Independência e Relações Sociais.

Em relação ao domínio Físico, os indivíduos com TB têm seu bem-estar físico e emocional afetado, uma vez que apresentam sintomas desconfortáveis e os medicamentos podem causar reações adversas durante todo o período de tratamento ${ }^{(14)}$.

As variáveis clínicas contagem de células T CD4, carga viral e uso de ARV, que não mostraram homogeneidade entre os grupos, têm sido fatores associados a piores escores no domínio Físico ${ }^{(15)}$. A imunossupressão provoca agravamento das condições clínicas, exacerbando os sintomas e aumentando a possibilidade de internação. Desta forma, a piora dos escores de QV no domínio Físico dos indivíduos com a coinfecção HIV/TB pode estar associada à sintomatologia da TB, à imunossupressão acentuada e ao não uso dos ARV.

Outro domínio em que houve diferença significante na média da QV dos grupos foi o Psicológico. Os avanços terapêuticos obtidos a partir da TARV resultaram em impacto importante na saúde física e psicológica das pessoas que vivem com HIV/aids, frente ao aumento da sobrevida, redução da mortalidade e diminuição do número de internações. Porém, na revelação do diagnóstico e durante um período no início do tratamento, o medo é uma constante junto aos pacientes devido ao fato de a associação entre aids e morte persistir nas representações populares.

Enquanto fato social, a aids, além do sofrimento causado pela doença em si, é potencializada pelo estigma e pelo preconceito, contribuindo para a morte social da pessoa e desencadeando estados de instabilidade emocional, episó- dios depressivos e sofrimento psíquico ${ }^{(16)}$, que se instalam principalmente logo após a descoberta do diagnóstico.

Por outro lado, o estigma social associado ao diagnóstico de TB em algumas culturas, é significativo. Indivíduos com TB podem se sentir isolados de sua família e amigos e experimentam o medo e a ansiedade de ter seu diagnóstico conhecido por outros ${ }^{(5)}$.

Atualmente, enfatiza-se a importância de fatores não biológicos determinantes da morbidade e da mortalidade em algumas enfermidades, como no caso da TB. A simples presença do bacilo de Koch não basta para causá-la. Freqüentemente, os fatores de ordem social, econômica e cultural têm que estar presentes para que a moléstia se desenvolva ${ }^{(17)}$.

Em revisão realizada sobre estudos de QV em pacientes com TB, os medicamentos tuberculostáticos mostraram efeito positivo na melhoria da QV dos pacientes, depreendendo-se que a saúde física parecia ser muito afetada pela doença, mas que melhorava rapidamente durante o tratamento, enquanto o comprometimento do bem-estar psicológico tendia a persistir por períodos maiores, inclusive após o término do tratamento ${ }^{(5)}$.

O domínio Relações Sociais também apresentou diferença estatisticamente significante entre os dois grupos. De modo geral, os processos de estigma e discriminação associados às dificuldades na revelação diagnóstica em espaços sociais como trabalho, família e amigos, tanto do HIV como da TB, podem afetar negativamente este domínio.

Estigma de saúde pode ser definido como um processo social caracterizado pela exclusão, rejeição e culpa, ou a desvalorização resultante da experiência de um julgamento social desfavorável por causa de uma condição de saúde particular ${ }^{(18)}$.

Em relação à TB, em estudo realizado em Santa Catari$\mathrm{na}^{(19)}$ observou-se que o preconceito contribuiu para o isolamento social, até mesmo de seus relacionamentos mais próximos, tais como cônjuges e filhos. O preconceito não é somente dos outros em relação a pessoa com tuberculose, mas é da própria pessoa, ancorada na sua concepção sobre a doença.

Pacientes com TB têm medo de transmitir a doença, principalmente no que diz respeito ao parceiro. Com medo de se sentir culpado, afasta-se de todos, ou seja, da família e do parceiro, levando-o ao isolamento e conseqüentemente à solidão. Quando trata-se de doença estigmatizante e embargada de preconceitos como a TB, observa-se que as reações negativas podem se sobrepor aos sentimentos e laços que envolvem a família e os amigos.

No entanto, em estudo realizado na Tailândia, observou-se que o maior estigma da aids na comunidade esteve associada com menor tempo na busca de cuidados para os sintomas da TB, sugerindo que estes pacientes procu- 
raram o cuidado na esperança de que seus sintomas seriam atribuídos à $T B$, e não à aids ${ }^{(20)}$.

Em um contexto da dupla infecção HIV/TB, o estigma da TB é considerado menor do que o da aids, uma vez que no início da epidemia de HIV/aids a doença esteve associada a grupos populacionais específicos, identificados a comportamentos transgressores. A trajetória da epidemia mostra que ocorreram muitas mudanças, principalmente na forma como ela está sendo vista pela sociedade; porém, grande parte dos indivíduos soropositivos esconde o fato de estarem infectados, pelo maior tempo e da melhor maneira possível, ingressando na clandestinidade quanto à sua condição, podendo levar ao isolamento social, à restrição dos relacionamentos sociais e às dificuldades no campo afetivo-sexual.

Os resultados apontam que a TB pode estar relacionada à pior QV no domínio Relações Sociais entre os coinfectados, tanto pela carga de estigma e preconceito que a doença carrega como pela sua própria manifestação clínica que provoca isolamento social.

O domínio Nível de Independência apresentou diferença estatisticamente significante entre os indivíduos com e sem a coinfecção. Foram encontrados na literatura, estudos que relacionam baixa escolaridade e renda com piores médias de QV neste domínio em indivíduos com $\mathrm{HIV}^{(3)}$ e coinfectados $\mathrm{HIV} / \mathrm{TB}^{(13)}$. A renda aparece como fonte de recursos materiais e nutricionais, e sua falta acarreta piora tanto no estado nutricional e quanto no imunológico.

Melhores médias de QV em Nível de Independência também foi fortemente associado ao uso da TARV ${ }^{(9)}$. Os medicamentos proporcionam a percepção de melhoria global de energia, capacidade de andar, aparência física, auto-estima, relações pessoais e vida sexual refletindo em melhores médias de $\mathrm{QV}^{(9)}$. A TB exige a tomada regular dos medicamentos, também melhorando significativamente os sintomas clínicos após o início do tratamento.

Embora os domínios Meio Ambiente e Espiritualidade tenham apresentado escores médios mais baixos nos coinfectados do que nos indivíduos sem TB, não foi encontrada diferença estatisticamente significante entre os grupos.

Também no domínio Meio Ambiente, os estudos relacionam melhores níveis socioeconômicos e educacionais com as maiores médias de $\mathrm{QV}^{(3,13)}$, sendo que esta associação também acontece com pacientes de outras doenças ou condições crônicas ${ }^{(21)}$.

A escolaridade e a renda podem estar relacionadas ao aspecto emocional e material, com os indivíduos apresentando melhores condições de vida para o enfrentamento da doença, e maiores recursos intelectuais para adaptação emocional diante das conseqüências da doença ${ }^{(22)}$.

As médias de QV do domínio Meio Ambiente encontradas acentuam o caráter de pauperização da epidemia de HIV/aids e relaciona a QV com as questões socioeconômicas.
Embora tenha havido diferença estatisticamente significante entre os grupos nas variáveis escolaridade e renda, não foi verificado a mesma diferença nas médias de QV deste domínio entre os indivíduos com e sem TB ativa, mesmo que com os coinfectados tenha sido ligeiramente mais baixa.

Na avaliação dos domínios de QV observou-se que o domínio Espiritualidade foi o que apresentou o maior escore médio entre todos os indivíduos, porém, não apresentou diferença com significância estatística entre os grupos.

A espiritualidade possui relação estreita com a meIhora da QV de pacientes com doenças crônicas. Estudos apontam que a religiosidade e espiritualidade em pessoas com HIV/aids podem auxiliar no ajustamento psicológico e no enfrentamento da doença ${ }^{(22)}$.

Viver com doença grave conduz a reajustamentos na vida cotidiana, assim como a redefinição de si mesmo e das relações com os outros. O contato com a idéia de morte pode gerar a necessidade de encontrar um significado para a vida, que muitas vezes é encontrado na vinculação com a espiritualidade $^{(15)}$. O bem-estar espiritual pode ser destacado como uma das variáveis presentes na capacidade de resiliência e proteção da saúde ${ }^{(15)}$; ele pode auxiliar as pessoas que vivem com HIV/aids na diminuição de agravos do processo saúde-doença, contribuindo para a melhoria da QV.

A realidade das pessoas que vivem em situações menos favorecidas, como é o caso da maioria dos indivíduos deste estudo, é de luta constante pela sobrevivência, muitas vezes mobilizando sentimentos de apego a uma crença religiosa. Além disso, a espiritualidade pode ser um grande auxílio para o enfrentamento da infecção pelo HIV, auxiliando na adaptação à nova realidade e suportando as privações e angústias impostas pela doença.

\section{CONCLUSÃO}

Diversos fatores biopsicossociais podem ser alterados no intercurso da coinfecção HIV/TB, dentre eles pode-se citar as conseqüências físico-orgânicas, as psicoafetivas e as comportamentais. Essas conseqüências tão evidentes no caso de doenças estigmatizadas, como é o caso da TB e da aids, alteram significativamente as diferentes dimensões da QV.

$\mathrm{Na}$ avaliação da qualidade da vida (QV) os indivíduos coinfectados apresentaram escores médios mais baixos do que os não coinfectados em todos os domínios, com diferença importante no Físico, Psicológico, Nível de Independência e Relações Sociais.

Faz-se presente a necessidade de desenvolver estratégias conjuntas de políticas que visem diminuir o impacto epidemiológico de uma doença sobre a outra, entre as quais detecção precoce do HIV e da TB, implantação da TARV, investigação da TB nos indivíduos soropositivos, tratamento da TB latente, ampliação do tratamento supervisionado, capacitação dos profissionais. 


\section{REFERÊNCIAS}

1. Rodrigues-Júnior AL, Ruffino-Netto A, Castilho EA. Distribuição espacial da coinfecção M.tuberculosis/HIV no Estado de São Paulo. Rev Saúde Pública. 2006;40(2):265-70.

2. Neves LA, Reis RK, Gir E. Compliance with the treatment by patients with the co-infection HIV/tuberculosis: integrative literature review. Rev Esc Enferm USP [Internet]. 2010 [cited 2011 Jan 17];44(4):1135-41. Available from: http://www.scielo.br/pdf/reeusp/v44n4/en_41.pdf

3. Reis RK, Santos CB, Dantas RAS, Gir E. Qualidade de vida, aspectos sociodemográficos e de sexualidade de pessoas vivendo com HIV/AIDS. Texto Contexto Enferm. 2011;20(3):565-75.

4. O'Connell K, Skevington S, Saxena S. Preliminary development of the World Health Organization's Quality of Life HIV instrument: analisys. Soc Sci. Med. 2003;57(7):1259-75.

5. Guo N, Marra F, Marra CA. Measuring health-related quality of life in tuberculosis: a systematic review. Health Qual Life Outcomes. 2009;18(1):7-14.

6. Muniyandi M, Rajeswari R, Balasubramanian R, Nirupa C, Gopi PG, Jaggarajamma K, et al. Evaluation of post-treatment health-related quality life (HRQoL) among tuberculosis patients. Int J Tuberc Lung Dis. 2007;11(8):887-92.

7. World Health Organization (WHO). Country protocol for developing the WHO quality of life (WHOQOL): HIV/aids module. Geneva; 1997.

8. Miranda AE, Golub JE, Lucena FF, Maciel EN, Gurgel MF, Dietze R. Tuberculosis and AIDS co-morbidity in Brazil: linkage of the tuberculosis and AIDS databases. Braz J Infect Dis. 2009;13(2):137-41.

9. Campos LN, César CC, Guimarães MD. Quality life among HIV-infected patients in Brazil after initiation of treatment. Clinics. 2009;64(9):867-75.

10. Neto LMS, Oliveira RVC, Totino PR, Sant'Anna FM, Coelho VO, Rolla VC, et al. Enteroparasitosis prevalence and parasitism influence in clinical outcomes of tuberculosis patients with or without HIV co-infection in a reference hospital in Rio de Janeiro (2000-2006). Braz J Infect Dis. 2009;13(6):427-32.
11. Bowkalowski C, Bertolozzi MR. Vulnerabilidades em pacientes com tuberculose no Distrito Sanitário de Santa Felicidade. Cogitare Enferm. 2010;15(1):92-9

12. Conde MB, Melo FAF, Marques AMC, Cardoso NC, Pinheiro VGF, Dalcin PTR, et al. III Diretrizes para Tuberculose da Sociedade Brasileira de Pneumologia e Tisiologia. J Bras Pneumol. 2009;35(10):1018-48.

13. Deribew A, Tesfaye M, Hailmichael $Y$, Negussu N, Daba $S$, Wogi $A$, et al. Tuberculosis and HIV co-infection: its impact on quality of life. Health Qual Life Outcomes. 2009;7:105.

14. Maciel ELN, Guidoni LM, Favero JL, Hadad DJ, Molino LP, Jonhson JL, et al . Efeitos adversos causados pelo novo esquema de tratamento da tuberculose preconizado pelo Ministério da Saúde do Brasil. J Bras Pneumol. 2010;36(2):232-8.

15. Calvetti PÜ, Muller MC, Nunes MLT. Qualidade de vida e bem-estar espiritual em pessoas vivendo com HIV/aids. Psicol Estudo. 2008;13(3):523-30.

16. Silva J, Saldanha AAW, Azevedo RLW.Variáveis de impacto na qualidade de vida de pessoas acima de 50 anos HIV+. Psicol Reflex Crit. 2010;23(1):56-63.

17. Severo NPF, Leite CQF, Capela MV, Simões MJS. Características clínico-demográficas de pacientes hospitalizados com tuberculose no Brasil. J Bras Pneumol. 2007;33(5): 565-71.

18. Weiss MG, Ramakrishna J. Stigma interventions and research for international health. Lancet. 2006;367(9509):536-8.

19. Souza SS, Silva DMGV, Meirelles BHS. Representações sociais sobre a tuberculose. Acta Paul Enferm. 2010;23(1):23-8.

20. Pungrassami P, Kipp AM, Stewart PW, Chongsuvivatwong V, Strauss RP, Van Rie A. Tuberculosis and aids stigma among patients who delay seeking care for tuberculosis symptoms. Int J Tuberc Lung Dis. 2010;14(2):181-7.

21. Alexandre TS, Cordeiro RC, Ramos LR. Fatores associados à qualidade de vida em idosos ativos. Rev Saúde Pública. 2009;43(4):613-21.

22. Seidl EMF. Enfrentamento, aspectos clínicos e sociodemográficos de pessoas vivendo com HIV/aids. Psicol Estudo. 2005;10(3):421-29.

Projeto com auxílio financeiro da Coordenação de Pessoal de Nível Superior (CAPES). Processo BEX 2447/09-6.

$\begin{array}{rr}\text { Rev Esc Enferm USP } & \text { Correspondência: Lis Aparecida de Souza Neves } \\ 2012 ; 46(3): 704-10 & \text { Rua Capitão Osório Junqueira, 1003 } \\ \text { www.ee.usp.br/reeusp/ } & \text { CEP 14076-060 - Ribeirão Preto, SP, Brasil }\end{array}$

